\title{
Quality of life in patients with food allergy
}

\author{
Darío Antolín-Amérigo ${ }^{1 *}$, Luis Manso², Marco Caminati ${ }^{3}$, Belén de la Hoz Caballer ${ }^{4}$, Inmaculada Cerecedo ${ }^{5}$, \\ Alfonso Muriel ${ }^{6}$, Mercedes Rodríguez-Rodríguez ${ }^{1}$, José Barbarroja-Escudero ${ }^{1}$, María José Sánchez-González ${ }^{1}$, \\ Beatriz Huertas-Barbudo ${ }^{2}$ and Melchor Alvarez-Mon ${ }^{1}$
}

\begin{abstract}
Food allergy has increased in developed countries and can have a dramatic effect on quality of life, so as to provoke fatal reactions. We aimed to outline the socioeconomic impact that food allergy exerts in this kind of patients by performing a complete review of the literature and also describing the factors that may influence, to a greater extent, the quality of life of patients with food allergy and analyzing the different questionnaires available. Hitherto, strict avoidance of the culprit food(s) and use of emergency medications are the pillars to manage this condition. Promising approaches such as specific oral or epicutaneous immunotherapy and the use of monoclonal antibodies are progressively being investigated worldwide. However, even that an increasing number of centers fulfill those approaches, they are not fully implemented enough in clinical practice. The mean annual cost of health care has been estimated in international dollars (I\$) 2016 for food-allergic adults and $\mathbf{\$} 1089$ for controls, a difference of $\mathbf{\$ 9 2 7}$ (95\% confidence interval I\$324-I\$1530). A similar result was found for adults in each country, and for children, and interestingly, it was not sensitive to baseline demographic differences. Cost was significantly related to severity of illness in cases in nine countries. The constant threat of exposure, need for vigilance and expectation of outcome can have a tremendous impact on quality of life. Several studies have analyzed the impact of food allergy on health-related quality of life (HRQL) in adults and children in different countries. There have been described different factors that could modify HRQL in food allergic patients, the most important of them are perceived disease severity, age of the patient, peanut or soy allergy, country of origin and having allergy to two or more foods. Over the last few years, several different specific Quality of Life questionnaires for food allergic patients have been developed and translated to different languages and cultures. It is important to perform lingual and cultural translations of existent questionnaires in order to ensure its suitability in a specific region or country with its own socioeconomic reality and culture. Tools aimed at assessing the impact of food allergy on HRQL should be always part of the diagnostic work up, in order to provide a complete basal assessment, to highlight target of intervention as well as to evaluate the effectiveness of interventions designed to cure food allergy. HRQL may be the only meaningful outcome measure available for food allergy measuring this continuous burden.
\end{abstract}

Keywords: Quality of life, Food allergy, Questionnaire, Specific questionnaire, Health-related quality of life (HRQL), Anaphylaxis

\section{Background}

Food allergy (FA) has increased in developed countries and can have a dramatic effect on quality of life, so as to

\footnotetext{
*Correspondence: dario.antolin@gmail.com

1 Servicio de Enfermedades del Sistema Inmune-Alergia, Hospital Universitario Príncipe de Asturias. Departamento de Medicina y Especialidades Médicas, Universidad de Alcalá, Carretera de Alcalá-Meco s/n, 28085 Alcalá de Henares, Madrid, Spain

Full list of author information is available at the end of the article
}

provoke fatal reactions [1-4]. We aimed to outline the socioeconomic impact that food allergy exerts in this kind of patients, by performing a complete review of the literature and also describing the factors that may influence, to a greater extent, the quality of life (QoL) of patients with food allergy. Moreover, the impairment in QoL may differ depending on the age, and as several specific questionnaires have been developed, we sought to describe into detail the different questionnaires available 
(Tables 1, 2, 3). Besides, as the terminology used with regards QoL is concrete and presumably complex, we wanted to clarify it, providing succinct definitions, for the sake of clarity (Table 4).

Hitherto, strict avoidance of the culprit food(s) and the use of emergency medications are the pillars to manage this condition $[3,5]$. Promising approaches such as specific oral or epicutaneous immunotherapy and the use of monoclonal antibodies are progressively being investigated worldwide. However, even that an increasing number of centers fulfill those approaches, they are not fully implemented enough in clinical practice.

The fact that neither the time of onset nor the intensity of the reaction is predictable can significantly influence QoL. Likewise, uncertainty when reading the ingredients and trace elements included in the food labelling on packaged food products may be bothersome for food allergic patients and their relatives [6]. The constant threat of exposure, need for vigilance and expectation of outcome can have a tremendous impact on their QoL $[7,8]$. Several studies have analyzed the impact of FA on health-related quality of life (HRQL) in adults and children in different countries [7-11] (Tables 1,2).

\section{Review}

\section{Quality of life in children with food allergy}

One of the most important issues about QoL in FA is to describe different predictors that shall contribute to modify HRQL. Identification of these predictors which have potential to decrease the patients' HRQL could improve allergic patients by means of implementing adequate and specific approaches. [11] (Table 3).

In addition, we have to mention that a proven diagnosis of FA does not seem to be an independent predictor of HRQL, when compared to self-reported or perceived FA [11]. Although, HRQL in caregivers is heterogeneous and worse in those that are not followed-up at a FA referral clinic, in a tertiary center [12]. It has been stated that parents report a lower impact on HRQL than their allergic children (considering a similar perception of the allergy severity) [13]. In this line, it has been observed that, caregivers without food-allergic children may have different coping strategies than caregivers with FA children, revealing the importance of providing specific FA education to caregivers [14].

An elegant multicenter, multinational study describes several predictors of health-related QoL in European children [15]. Perceived disease severity, having a peanut or soy allergy, and the country of origin should be considered as contributors of the variance in HRQL (Table 3). Likewise, children with more than two food allergies had lower values of QoL scores compared with those with one or two food allergies [16]. Additionally, it has been observed that older children, the ones with severe systemic reactions, or those with mothers or siblings also affected by allergies, as well as girls, and children with multiple food allergies showed worse QoL scores [17].

Oral immunotherapy for different foods has been found to result in HRQL improvement, at least in participants with peanut or cow milk allergy $[18,19]$. It has also been observed in a study comprising food-allergic children, where multiple-oral immunotherapies led to improvement in caregiver HRQL [20].

HRQL in food-allergic patients should be measured to have a global assessment of these patients, and for this reason specific questionnaires have been developed in recent times (Tables 1,2 ), to be completed by parents $[21,22]$, but some of them also by children [23, 24]. These questionnaires should be short and easy to complete, to become both a useful and a suitable tool for evaluation of patients with food allergy.

One of the most used food allergy-related QoL questionnaires in children is probably the Food Allergy Quality of Life Questionnaire (FAQLQ), which was developed and validated in Europe as a part of the EuroPrevall Project. These questionnaires include versions for children from 0 to 18 years old and for their parents [25]. But there are also other questionnaires that could be employed, for example the Food Allergy Quality of LifeParental Burden (FAQL-PB) Questionnaire [26] developed in the US or the Food Allergy Self-Efficacy scale for Parents (FASE-P) that have been proved to be useful to identify areas where parents have less confidence in managing their child's FA [22]. All these questionnaires have demonstrated good internal consistency (measured as Cronbach's $\alpha$ ), as well as good correlation with other generic and FA QoL questionnaires (Table 4).

It is important to perform lingual and cultural translations of existent questionnaires in order to ensure their suitability in a specific region or country, with its own socioeconomic reality and culture [27-29].

Briefly, for children there are general food questionnaire items that impair QoL to a greater extent, namely, "able to eat fewer products" and "always be alert as to what you are eating", included in Allergen Avoidance and Dietary Restrictions domain; and the item "change of ingredients of a product" related with Risk of Accidental Exposure domain. The FAQLQ-PF showed that psychosocial impact in food-allergic children exerted a severe impact of on HRQL, due to the anxiety about food issues and the risk of a potential reaction [21] (Table 1).

\section{Quality of Life in Teenagers with Food Allergy}

It is estimated that around $2 \%$ of adolescents suffer from FA [30]. In healthy individuals the adolescence is a very critical time, characterized by accelerated growth 


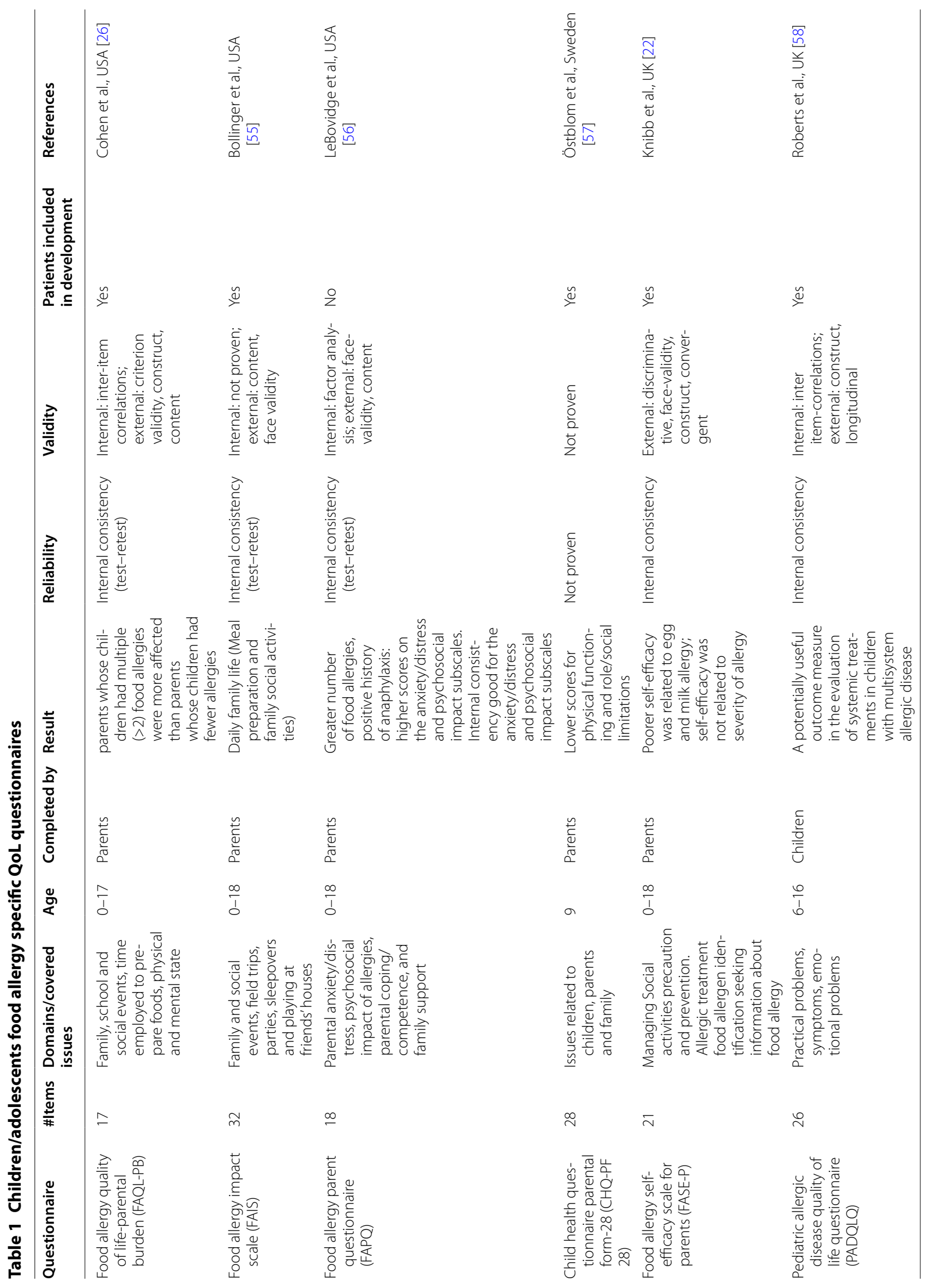




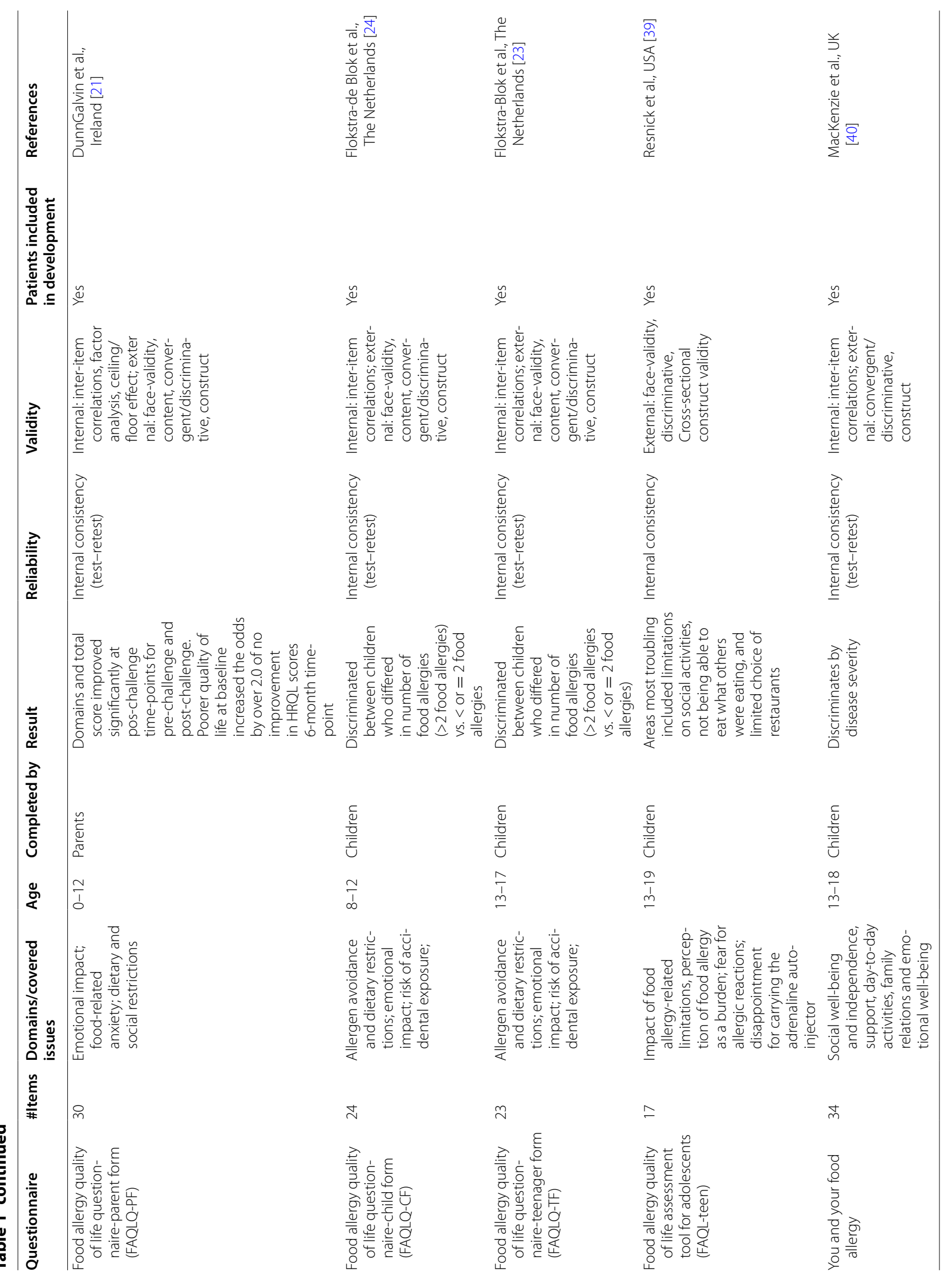




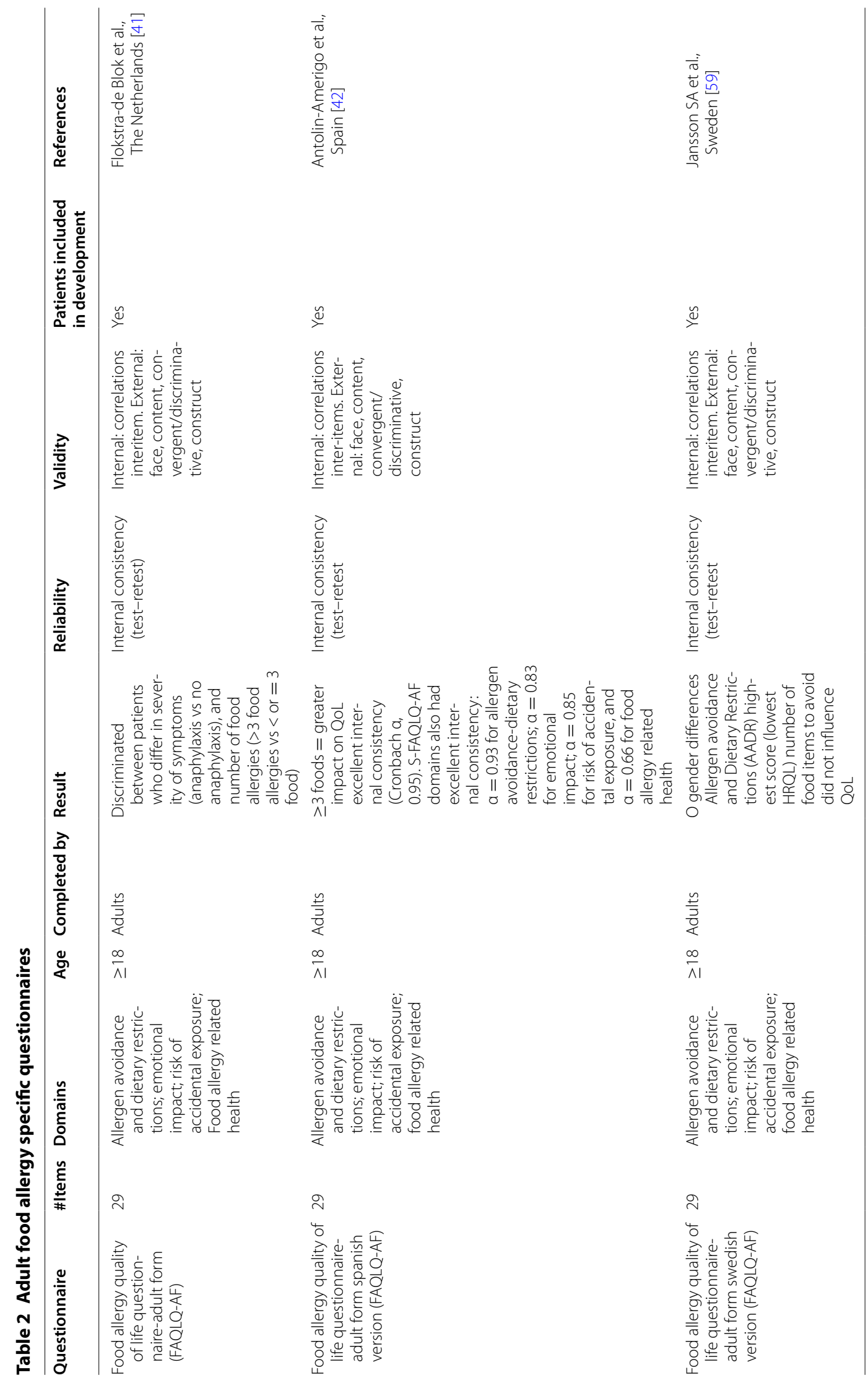


Table 3 Factors with statistical significance that affect QoL in Fa

\begin{tabular}{|c|c|c|c|}
\hline \# & Factor & Article & Reference \\
\hline 1 & Constant vigilance in the avoidance of specific foods to prevent an allergic reaction & Carrard et al. & {$[60]$} \\
\hline 2 & Management of an acute reaction & Carrard et al. & {$[60]$} \\
\hline 3 & Experience of anaphylaxis has a limited impact in QoL & Saleh-Langenberg et al. & {$[15,36]$} \\
\hline 4 & $\begin{array}{l}\text { Allergies to fish and milk in adults and peanuts and soy in children caused greater HRQL impairment } \\
\text { as compared to other foods }\end{array}$ & Saleh-Langenberg et al. & {$[15,36]$} \\
\hline 5 & $\begin{array}{l}\text { Performing food challenge improved QoL irrespective of the outcome of the challenge (waines after } \\
6 \text { months in allergic patients) }\end{array}$ & Soller et al. & {$[49]$} \\
\hline 6 & Perceived disease severity & Saleh-Langenberg et al. & {$[15,36]$} \\
\hline 7 & Country of origin & Saleh-Langenberg et al. & {$[15,36]$} \\
\hline 8 & Children $>2$ allergies & Sicherer et al. & {$[3]$} \\
\hline 9 & Older children and those with mother or siblings affected by allergies & Wassenberg et al. & {$[17]$} \\
\hline 10 & Oral induction of Tolerance (OIT) with peanut or cow milk: improves QoL & Factor JM et al., Carraro S et al. & {$[18,19]$} \\
\hline
\end{tabular}

and tremendous physiological, neurocognitive and emotional changes. In this context, chronic diseases like FA can have an even higher impact on the individual's development and future wellbeing. Social isolation, depression, difficulties in school performance and leisure activities have been reported by food allergic adolescents as a result of their disease, along with the fear of allergic reactions [31-33]. On the other side, it is well known that a kind of incorrect belief of lack of risk leads teenagers to underestimate the severity of FA, as they think they will not die from any cause. It might result in risk-taking behaviours that can increase the risk of dying from FA [32, 34]. One of the major consequences is the reluctance to carry an epinephrine auto-injector, because the treatment is considered burdensome or simply not needed [35, 36]. According to recent data, the perceived burden of treatment is not directly associated with the overall HRQL, disease severity or trait anxiety, but it does significantly affect the non-compliance attitude towards epinephrine auto-injector and food restrictions [36]. Furthermore, a significant disagreement on health-related quality of life, mainly associated with adolescents' rather than parents' perceptions and characteristics, has been highlighted between parents and affected teenagers. Parents may not recognize the social impact of food restrictions or annoyance at having to carry selfinjectable adrenaline [31, 37].

Up to now three tools for assessing HRQL in food allergic adolescents have been validated and can be used as reliable tool in daily clinical practice (Table 1 ).

It has been observed that UK and US teenagers, but not the Dutch ones, consider of primary importance the impact of FA on their social activities. US adolescents perceive their FA as a burden to others, but UK and Dutch teenagers do not confirm it. Dutch adolescents only experience the risk of accidental exposure as a concern. Support in managing FA is highly considered by UK teenagers but it does not appear to be the case for the Dutch and US ones [23, 38-40]. For these reasons the development of country-specific tools for assessing FA-related QoL should be one of the priorities in the FA management.

\section{Quality of life in adults with food allergy}

Studies on food-allergic adult patients assessing QoL are scarce [41, 42] and the impact could be influenced by the fact that patients who have sought for medical help could have a worse QoL than those who have not actively looked for medical assessment [42, 43] (Table 2).

The Food Allergy Quality of Life Questionnaire-Adult Form (FAQLQ-AF) showed that uncertainty and anxiety seem to account for the greatest impact on HRQL in European food-allergic adults [7, 41, 42] (Table 2). Notwithstanding, both uncertainty and anxiety decreased in patients who underwent a double-blinded, placebo-controlled food challenge in the Netherlands [44].

The FAQLQ-AF is available for adults and was developed and validated in the context of the EuroPrevall Project, a multicenter European FA research project which objectives include analyzing the impact of food allergies on quality of life. It is currently available in several European languages [7-9, 41, 42] (Table 2).

Construct validity of the FAQLQ-AF was assessed in patients from eight European countries, resulting as strong to very strong (Fig. 1). Moreover, internal consistency was excellent in all eight countries. A very interesting finding was that participants from eight European countries did not have comparable HRQL (as measured with total FAQLQ-AF scores). This result reinforces the value of the instrument, as it proves its sensitivity for differences in HRQL between populations with different socio-economic backgrounds [7] (Table 2). 


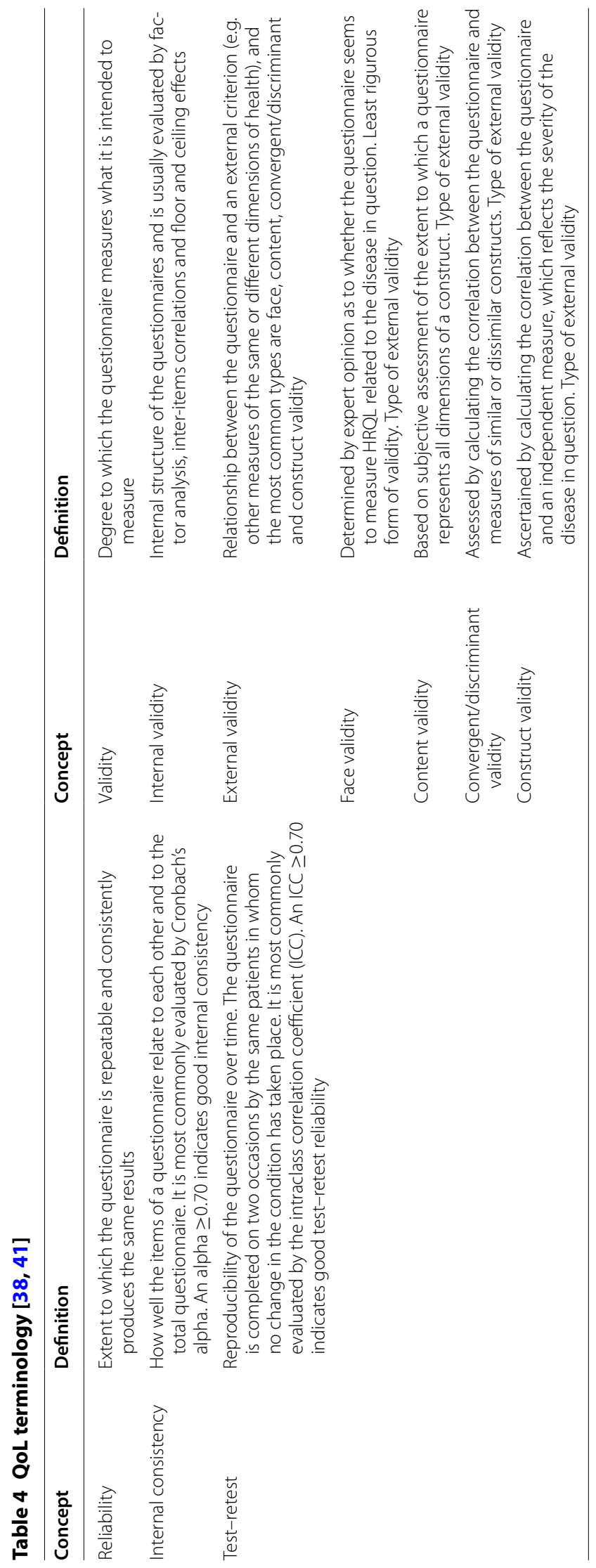




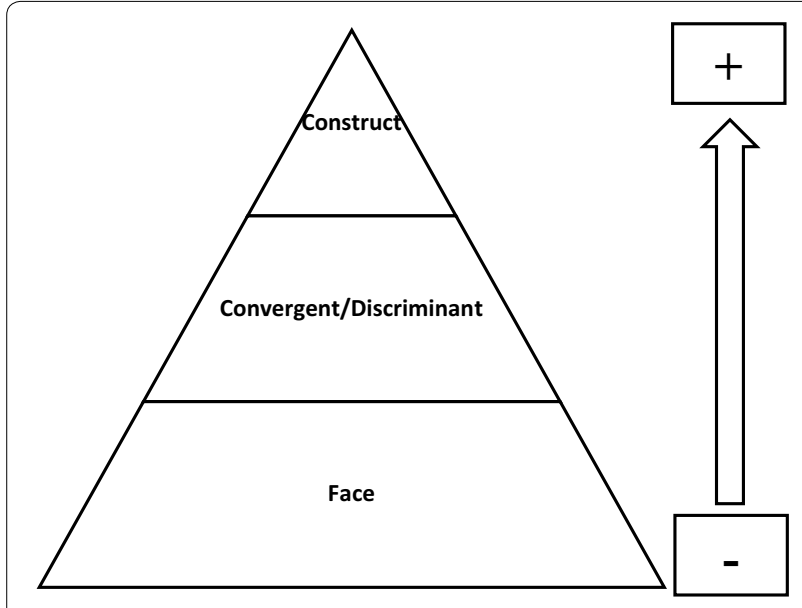

Fig. 1 Different forms of external validity based on the rigor of the method of ascertainment

In addition, studies have found significant differences in HRQL between countries, even when corrected for differences in perceived disease severity [15]. To unveil this aspect, Saleh-Langenberg et al. recruited a total of 648 European food-allergic patients (404 adults, 244 children) whom completed an age-specific questionnaire package including descriptive questions. Unexpectedly, the authors found that both for adults and children neither experiencing anaphylaxis nor being prescribed an epinephrine auto-injector (EAI) contributed to impairment of HRQL [15]. On the other hand, previous studies have shown that both confirmed and perceived FA impair equally HRQL [45].

The culture and traditions of eating might vary among different countries [42,46], consequently, the impact of FA on quality of life shall diverge. Another important outcome was that forty-seven percent of all participants who reported anaphylaxis and who were diagnosed by a health care professional were not prescribed an epinephrine auto-injector, which corroborates previous findings about the suboptimal management of acute food-allergic reactions by both patients and physicians [47].

Other authors have suggested that as individual's age, they probably become more aware of the severity of symptoms and may take into account the threatening effect of FA [42].

The healthcare cost in terms of FA has been investigated, in an elegant patient-based cost study. It has been reported that adults with 'possible' food allergy visited health professionals, on average, $11.17(\mathrm{SD}=16.14)$ times per year compared with $7.11(\mathrm{SD}=12.80)$ visits per year reported by controls. Similarly, children with 'possible' FA visited health professionals 10.75 times per year $(\mathrm{SD}=13.23)$ compared with $6.56(\mathrm{SD}=9.78)$ visits per year reported by controls. Consequently, food-allergic individuals had higher health care costs than controls. The mean annual cost of health care was international dollars (I\$) 2016 for food-allergic adults and I\$1089 for controls, a difference of I\$927 (95\% confidence interval I\$324-I\$1530). A similar result was found for adults in each country, and for children, and interestingly, it was not sensitive to baseline demographic differences. Cost was significantly related to severity of illness in cases in nine countries [48].

In another study, QoL in adults with peanut allergy was compared with other disease groups. In contrast to children, the former group was observed to have better QoL than rheumatologic patients [45].

In addition, in a large population survey performed in Canada, individuals of low education and new Canadians self-reported fewer allergies, which may be due to genetics, environment, lack of appropriate health care, or lack of awareness of allergies, which could eventually reduce self-report [49].

Just to underline the impact that FA exerts in foodallergic patients, access to a 24-h telephone hotline specifically designed for this kind of patients in Ireland, significantly improved the measured QoL, and continued to do so for 6 months after the study time, even just two out of the 24 patients actually used it [50].

Moreover, some studies have shown the long-term positive effect food challenges yield on QoL. Unpredictably, this positive effect was not conditioned by the outcome of food challenges $[51,52]$.

\section{Conclusions}

FA is suffered by patients but also by their relatives, friends and acquaintances $[16,26,53]$ (Tables 1, 2). There have been described different factors that could modify HRQL in food allergic patients, considering as the most influential: perceived disease severity, age of the patient, peanut or soy allergy, country of origin and having allergy to two or more foods. Nevertheless, further studies are necessary to elucidate all these predictors and to achieve a good HRQL in food-allergic patients.

Over the last few years, several different specific QoL questionnaires for food-allergic patients have been developed and translated to different languages and cultures (Fig. 1). Tools designed to assess the impact of FA on HRQL should be always part of the diagnostic work up, in order to provide a complete basal assessment, to highlight target of intervention as well as to evaluate the effectiveness of interventions designed to cure FA [54-60]. HRQL may be the only meaningful outcome measure suitable and available for FA, measuring this continuous burden. 


\section{Authors' contributions}

All the authors have collaborated in searching the bibliography and writing the manuscript. All authors read and approved the final manuscript.

\section{Author details}

1 Servicio de Enfermedades del Sistema Inmune-Alergia, Hospital Universitario Príncipe de Asturias. Departamento de Medicina y Especialidades Médicas, Universidad de Alcalá, Carretera de Alcalá-Meco s/n, 28085 Alcalá de Henares, Madrid, Spain. ${ }^{2}$ Hospital del Sureste. Arganda del Rey, Unidad de Alergia, Madrid, Spain. ${ }^{3}$ Allergy Unit, Verona University and General Hospital, Verona, Italy. ${ }^{4}$ Servicio de Alergia, Hospital Universitario Ramón y Cajal, IRYCIS, Madrid, Spain. ${ }^{5}$ Servicio de Alergia, Hospital Universitario Clínico San Carlos, Madrid, Spain. ${ }^{6}$ Unidad de Bioestadística Clínica, Hospital Universitario Ramón y Cajal, IRYCIS, Madrid, Spain

\section{Acknowledgements}

This work was partially supported by a grant from Comunidad de Madrid S2010/BMD-2502 MITIC and also FIS PI11/02758 and EUROPREVALL FP6-CT-2005-514000.

\section{Competing interests}

The authors declare that they have no competing interests.

Received: 19 December 2015 Accepted: 27 January 2016 Published online: 17 February 2016

\section{References}

1. Vieths S, Reese G, Ballmer-Weber BK, Beyer K, Burney P, Fernandez-Rivas $M$, et al. The serum bank of EuroPrevall-the prevalence, cost and basis of food allergy across Europe. Food Chem Toxicol. 2008;46(Suppl 1):12-4

2. Muraro A, Roberts G, Worm M, Bilo MB, Brockow K, Fernandez Rivas M Santos AF, Zolkipli ZQ, Bellou A, Beyer K, Bindslev-Jensen C, Cardona V, Clark AT, Demoly P, Dubois AE, DunnGalvin A, Eigenmann P, Halken S, Harada L, Lack G, Jutel M, Niggemann B, Rueff F, Timmermans F, VliegBoerstra BJ, Werfel T, Dhami S, Panesar S, Akdis CA, Sheikh A, EAACI Food Allergy and Anaphylaxis Guidelines Group. Anaphylaxis: guidelines from the European academy of allergy and clinical immunology. Allergy. 2014;69:1026-45

3. Sicherer SH. Epidemiology of food allergy. J Allergy Clin Immunol. 2011:127:594-602.

4. Ben-Shoshan M, Turnbull E, Clarke A. Food allergy: temporal trends and determinants. Curr Allergy Asthma Rep. 2012;12:346-72.

5. Fernandez Rivas M. Food allergy in alergologica-2005. J Investig Allergol Clin Immunol. 2009:19(Suppl 2):37-44.

6. Barnett J, Leftwich J, Muncer K, Grimshaw K, Shepherd R, Raats MM, et al How do peanut and nut-allergic consumers use information on the packaging to avoid allergens? Allergy. 2011;66:969-78.

7. Goossens NJ, Flokstra-de Blok BM, van der Meulen GN, Arnlind MH, Asero R, Barreales $L$, et al. Health-related quality of life in food-allergic adults from eight European countries. Ann Allergy Asthma Immunol. 2014;113(63-8):e1.

8. de Blok BM, Vlieg-Boerstra BJ, Oude Elberink JN, Duiverman EJ, DunnGalvin A, Hourihane JO, et al. A framework for measuring the social impact of food allergy across Europe: a EuroPrevall state of the art paper. Allergy. 2007;62:733-7.

9. Flokstra-de Blok BMJ, van der Velde JL, Vlieg-Boerstra BJ, Oude Elberink JNG, DunnGalvin A, Hourihane JO, et al. Health-related quality of life of food allergic patients measured with generic and disease-specific questionnaires. Allergy. 2010;65:1031-8.

10. Flokstra-de Blok BMJ, Dubois AEJ, Vlieg-Boerstra BJ, Oude Elberink NG, Raat H, DunnGalvin A, et al. Health-related quality of life of food allergic patients: comparison with the general population and other diseases. Allergy. 2010;65:238-44.

11. Venter C, Sommer I, Moonesinghe H, Grundy J, Glasbey G, Patil V, et al. Health-Related Quality of Life in children with perceived and diagnosed food hypersensitivity. Pediatr Allergy Immunol. 2015;26:126-32 (Epub ahead of print).
12. Ward C, Greenhawt M. Differences in caregiver food allergy quality of life between a tertiary care, specialty clinic, and a caregiver reported food allergic populations. J Allergy Clin Immunol Pract. 2015;. doi:10.1016/j. jaip.2015.07.023.

13. van der Velde JL, Flokstra-de Blok BM, Dunngalvin A, Hourihane JO, Duiverman EJ, Dubois AE. Parents report better health-related quality of life for their food-allergic children than children themselves. Clin Exp Allergy. 2011;41:1431-9.

14. Yamamoto-Hanada K, Futamura M, Takahashi O, Narita M, Kobayashi F, Ohya Y. Caregivers of children with no food allergy-their experiences and perception of food allergy. Pediatr Allergy Immunol. 2015;26:614-7.

15. Saleh-Langenberg J, Goossens NJ, Flokstra-de Blok BM, Kollen BJ, van der Meulen GN, Le TM, Knulst AC, et al. Predictors of health-related quality of life of European food-allergic patients. Allergy. 2015;70:616-24.

16. Sicherer SH, Noone SA, Muñoz-Furlong A. The impact of childhood food allergy on quality of life. Ann Allergy Asthma Immunol. 2001;87:461-4.

17. Wassenberg J, Cochard MM, Dunngalvin A, Ballabeni P, Flokstra-de Blok BM, Newman CJ, et al. Parent perceived quality of life is age-dependent in children with food allergy. Pediatr Allergy Immunol. 2012;23:412-9.

18. Factor JM, Mendelson L, Lee J, Nouman G, Lester MR. Effect of oral immunotherapy to peanut on food-specific quality of life. Ann Allergy Asthma Immunol. 2012;109:348-52.

19. Carraro S, Frigo AC, Perin M, Stefani S, Cardarelli C, Bozzetto S, et al. Impact of oral immunotherapy on quality of life in children with cow milk allergy: a pilot study. Int J Immunopathol Pharmacol. 2012;25:793-8.

20. Otani IM, Bégin P, Kearney C, DominguezTL, Mehrotra A, Bacal LR, et al. Multiple-allergen oral immunotherapy improves quality of life in caregivers of food-allergic pediatric subjects. Allergy Asthma Clin Immunol. 2014;10:25.

21. DunnGalvin A, Cullinane C, Daly DA, Flokstra-de Blok BM, Dubois AE, Hourihane JO. Longitudinal validity and responsiveness of the Food allergy quality of life questionnaire-Parent Form in children 0-12 years following positive and negative food challenges. Clin Exp Allergy. 2010:40:476-85.

22. Knibb RC, Barnes C, Stalker C. Parental confidence in managing food allergy-development and validation of the food allergy self-efficacy scale for parents (FASE-P). Clin Exp Allergy. 2015;45:1681-9.

23. Flokstra-de Blok BM, DunnGalvin A, Vlieg-Boerstra BJ, Oude Elberink JN, Duiverman EJ, Hourihane JO, et al. Development and validation of the self-administered Food allergy quality of life questionnaire for adolescents. J Allergy Clin Immunol. 2008;122:139-44.

24. Flokstra-de Blok BM, DunnGalvin A, Vlieg-Boerstra BJ, Oude Elberink JN, Duiverman EJ, Hourihane JO, et al. Development and validation of a selfadministered food allergy quality of life questionnaire for children. Clin Exp Allergy. 2009:39:127-37.

25. Flokstra-de Blok BM, Dubois AE. Quality of life measures for food allergy. Clin Exp Allergy. 2012:42:1014-20.

26. Cohen BL, Noone S, Muñoz-Furlong A, Sicherer SH. Development of a questionnaire to measure quality of life in families with a child with food allergy. J Allergy Clin Immunol. 2004;114:1159-63.

27. Teixeira IP, Novais Ide P, Pinto Rde M, Cheik NC. Cultural adaptation and validation of the KINDL questionnaire in Brazil for adolescents between 12 and 16 years of age. Rev Bras Epidemiol. 2012;15:845-57.

28. Chen YM, He LP, Mai JC, Hao YT, Xiong LH, Chen WQ, et al. Validity and reliability of pediatric quality of life inventory version 4.0 generic core scales in Chinese children and adolescents. Zhonghua Liu Xing Bing Xue Za Zhi. 2008;29:560-3.

29. Rajmil L, Serra-Sutton V, Fernandez-Lopez JA, Berra S, Aymerich M, Cieza A, et al. The Spanish version of the German health-related quality of life questionnaire for children and adolescents: the Kindl. An Pediatr (Barc). 2004:60:514-21.

30. Pereira B, Venter C, Grundy J, Clayton CB, Arshad HS, Dean T. Prevalence of sensitization to food allergens, reported adverse reactions to foods, food avoidance, and food hypersensitivity among teenagers. J Allergy Clin Immunol. 2005;116:884-92.

31. Cummings AJ, Knibb RC, King RM, Lucas JS. The psychosocial impact of food allergy and food hypersensitivity in children, adolescents and their families: a review. Allergy. 2010;65:933-45.

32. MacKenzie H, Roberts $G$, van Laar D, Dean T. Teenagers' experiences of living with food hypersensitivity: a qualitative study. Pediatr Allergy Immunol. 2010;21:595-602. 
33. Sommer I, Mackenzie $H$, Venter C, Dean T. An exploratory investigation of food choice behavior of teenagers with and without food allergies. Ann Allergy Asthma Immunol. 2014;112:446-52.

34. Monks H, Gowland MH, Mackenzie H, Erlewyn-Lajeunesse M, King R, Lucas JS, et al. How do teenagers manage their food allergies? Clin Exp Allergy. 2010;40:1533-40.

35. Flokstra-de Blok BM, Doriene van Ginkel C, Roerdink EM, Kroeze MA, Stel AA, van der Meulen GN, et al. Extremely low prevalence of epinephrine auto injectors in high-risk food-allergic adolescents in Dutch high schools. Pediatr Allergy Immunol. 2011;22:374-7.

36. Saleh-Langenberg J, Flokstra-de Blok BM, Goossens NJ, Kemna JC, van der Velde JL, Dubois AE. The compliance and burden of treatment with the epinephrine auto-injector in food-allergic adolescents. Pediatr Allergy Immunol. 2015 Aug 13. [Epub ahead of print].

37. van der Velde JL, Flokstra-de Blok BM, Hamp A, Knibb RC, Duiverman EJ, Dubois AE. Adolescent-parent disagreement on health-related quality of life of food-allergic adolescents: who makes the difference? Allergy. 2011;66:1580-9.

38. Salvilla SA, Dubois AE, Flokstra-de Blok BM, et al. Disease-specific health related quality of life instruments for lgE-mediated food allergy. Allergy. 2014;69:834e84

39. Resnick ES, Pieretti MM, Maloney J, Noone S, Muñoz-Furlong A, Sicherer $\mathrm{SH}$. Development of a questionnaire to measure quality of life in adolescents with food allergy: the FAQL-teen. Ann Allergy Asthma Immunol. 2010;105:364-8.

40. Mackenzie H, Roberts G, Van Laar D, Dean T. A new quality of life scale for teenagers with food hypersensitivity. Pediatr Allergy Immunol. 2012;23:404-11

41. Flokstra-de Blok BM, van der Meulen GN, DunnGalvin A, Vlieg-Boerstra BJ, Oude Elberink JN, Duiverman EJ, et al. Development and validation of the food allergy quality of life questionnaire-adult form. Allergy. 2009;64:1209-17.

42. Antolin-Amerigo D, Cerecedo Carballo I, Muriel A, Fernández-Rivas M, Diéguez Pastor M, Flokstra-de Blok B, et al. Validation of the Spanish version of the food allergy quality of life questionnaire-adult form (S-FAQLQAF). J Investig Allergol Clin Immunol. 2015;25:270-5.

43. Lange L. Quality of life in the setting of anaphylaxis and food allergy. Allergo J Int. 2014;23:252-60.

44. van der Velde JL, Flokstra-de Blok BM, de Groot H, Oude-Elberink JN, Kerkhof M, Duiverman EJ, et al. Food allergy-related quality of life after double-blind, placebo-controlled food challenges in adults, adolescents, and children. J Allergy Clin Immunol. 2012;130(5):1136-1143e2.

45. Primeau MN, Kagan R, Joseph L, Lim H, Dufresne C, Duffy C, et al. The psychological burden of peanut allergy as perceived by adults with peanut allergy and the parents of peanutallergic children. Clin Exp Allergy. 2000;30:1135-43.

46. Goossens NJ, Flokstra-de Blok BM, Vlieg-Boerstra BJ, Duiverman EJ, Weiss CC, Furlong TJ, et al. Online version of the food allergy quality of life questionnaire-adult form: validity, feasibility and cross-cultural comparison. Clin Exp Allergy. 2011;41:574-81.
47. Le TM, van Hoffen E, Pasmans SG, Bruijnzeel-Koomen CA, Knulst AC. Suboptimal management of acute food-allergic reactions by patients, emergency departments and general practitioners. Allergy. 2009;64:1227-8.

48. Fox M, Mugford M, Voordouw J, Cornelisse-Vermaat J, Antonides G, de la Hoz Caballer B, et al. Health sector costs of self-reported food allergy in Europe: a patient-based cost of illness study. Eur J Public Health. 2013;23:757-62

49. Soller L, Ben-Shoshan M, Harrington DW, Knoll M, Fragapane J, Joseph $L$, et al. Prevalence and predictors of food allergy in Canada: a focus on vulnerable populations. J Allergy Clin Immunol Pract. 2015;3:42-9.

50. Kelleher MM, Dunngalvin A, Sheikh A, Cullinane C, Fitzsimons J, Hourihane JO. Twenty four-hour helpline Access to expert management advice for food-allergy-triggered anaphylaxis in infants, children and young people: a pragmatic, randomized controlled trial. Allergy. 2013;68:1598-604.

51. van der Velde JL, Flokstra-de Blok BM, de Groot H, Oude-Elberink JN, Kerkhof M, Duiverman EJ, et al. Food allergy related quality of life after double-blind, placebo-controlled food challenges in adults, adolescents, and children. J Allergy Clin Immunol. 2012;130:1136-43.

52. Knibb RC, Ibrahim NF, Stiefel G, Petley R, Cummings AJ, King RM, et al. The psychological impact of diagnostic food challenges to confirm the resolution of peanut or tree nut allergy. Clin Exp Allergy. 2012;42:451-9.

53. Marklund B, Ahlstedt S, Nordström G. Health-related quality of life among adolescents with allergy-like conditions-with emphasis on food hypersensitivity. Health Qual Life Outcomes. 2004;2:65.

54. Muraro A, Dubois AE, DunnGalvin A, Hourihane JO, de Jong NW, Meyer R, Panesar SS, Roberts G, Salvilla S, Sheikh A, Worth A, Flokstra-de Blok BM, European Academy of Allergy and Clinical Immunology. EAACl food allergy and anaphylaxis guidelines. food allergy health-related quality of life measures. Allergy. 2014;69:845-53.

55. Bollinger M, Dahlquist L, Mudd K, Sonntag C, Dillinger L, McKenna K. The impact of food allergy on the daily activities of children and their families. Ann Allergy Asthma Immunol. 2006;96:415-21.

56. Lebovidge JS, Stone KD, Twarog FJ, Raiselis SW, Kalish LA, Bailey EP, Schneider LC. Development of a preliminary questionnaire to assess parental response to children's food allergies. Ann Allergy Asthma Immunol. 2006;96:472-7.

57. Ostblom E, Egmar AC, Gardulf A, Lilja G, Wickman M. The impact of food hypersensitivity reported in 9-year-old children by their parents on health-related quality of life. Allergy. 2008;63:211-8.

58. Roberts G, Hurley C, Lack G. Development of a quality-of-life assessment for the allergic child or teenager with multisystem allergic disease. J Allergy Clin Immunol. 2003;111:491-7.

59. Jansson SA, Heibert-Arnlind M, Middelveld RJ, Bengtsson UJ, Sundqvist AC, Kallström-Bengtsson I. Health-related quality of life, assessed with a disease-specific questionnaire, in Swedish adults suffering from welldiagnosed food allergy to staple foods. Clin Transl Allergy. 2013;3:21.

60. Carrard A, Rizzuti D, Sokollik C. Update on food allergy. Allergy. 2015;70(12):1511-20.

\section{Submit your next manuscript to BioMed Central and we will help you at every step:}

- We accept pre-submission inquiries

- Our selector tool helps you to find the most relevant journal

- We provide round the clock customer support

- Convenient online submission

- Thorough peer review

- Inclusion in PubMed and all major indexing services

- Maximum visibility for your research

Submit your manuscript at www.biomedcentral.com/submit

C Biomed Central 